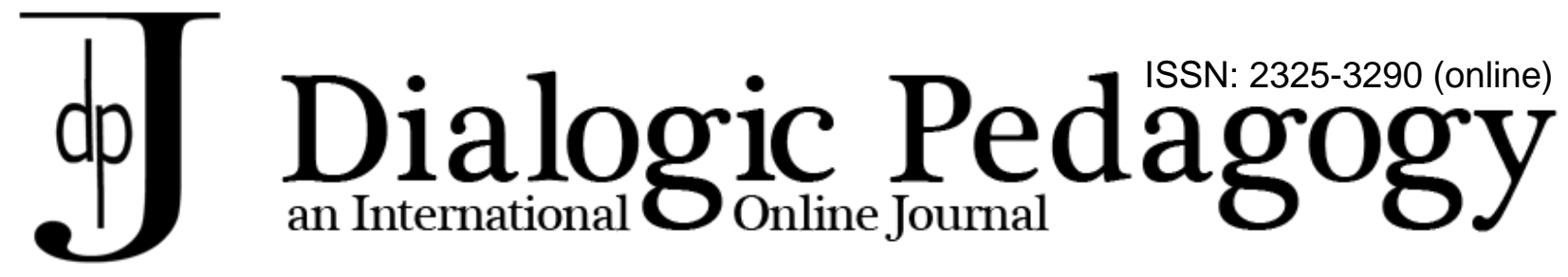

\title{
Dialogical Grammar: Varieties of Dialogue in Wittgenstein's Methodology
}

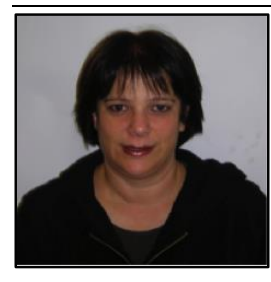

Dorit Lemberger

Bar-Ilan university

\begin{abstract}
The dialogical character of Wittgenstein's Philosophical Investigations has received scant attention in the literature, given the work's status in his total oeuvre, and is dismissed as a marginal as compared to the other differences between the Tractatus and the Investigations. The main lines of interpretation that have been proposed see dialogue as a rhetorical technique intended to present erroneous positions and then refute them, as an exemplification of what can be expressed in language (McGinn 1997; Rhees 1998), or as a reflection of Wittgenstein's informal teaching method (Malcolm 2001; Savickey et al. 1990). The present article adopts the perspective that Wittgenstein's use of dialogue makes it possible to track the various modes of language-acts, consonant with his directions to examine the daily use of language (Wittgenstein 2009, §116 and esp. §132), "when language is, as it were, idling." In his later inquiries, Wittgenstein frequently considers the nature of mental states, accompanied by an attempt to characterize the differences between them while at the same time dealing with the cases in which it is difficult to distinguish them. In this process he made a variety of uses of dialogue, each of which embodies a different aspect of language action. Subsequently I will demonstrate that these different uses are not haphazard. A scrutiny of the nature of the dialogue can help us understand the nature of the activity carried out of the state of consciousness. Finally, I propose a distinction among three main types of dialogue: technical, conversational, and reflexive.
\end{abstract}

Key Words: technical dialogue; conversational dialogue; reflexive dialogue

Dorit Lemberger (Ph.D.) has been at Bar-llan University since 2005. Dr. Lemberger is a lecturer in the Hermeneutics and Cultural studies, Interdisciplinary unit, with research interests in philosophy of language and literary studies. 


\section{Introduction}

A close look at Wittgenstein's use of dialogue can make a major contribution to clarifying the nature of dialogism, for two reasons. The first part of Wittgenstein's magnum opus, Philosophical Investigations ${ }^{1}$, is written as a dialogue (Wittgenstein was not responsible for the format of the second part; see $n$. 1). In the introduction to the fourth edition, the editors stressed the need for a new translation that would adjust the grammar and syntax to coincide with the conversational tone. ${ }^{2}$ In practice, as early as his Vienna Circle period Wittgenstein employed a dialogical and conversational method (Wittgenstein 2003), marked by questions and answers and the use of dialogical terminology such as "aspect" and "game," as will be discussed below.

His disciples edited others of his works, too, as conversations that reflect how Wittgenstein taught and interacted with them. ${ }^{3}$ Because dialogue is a form both of writing and of oral instruction, a separate discussion, going beyond what has been carried out thus far, about the relationship between the dialogical nature of writing and teaching, on the one hand, and the content, on the other-that is, the ways in which language works - seems to be in order. ${ }^{4}$ Although much has been written about Wittgenstein's philosophical language, his choice of the dialogue method is perceived as a rhetorical technique to persuade us of the correctness of a certain position, as an exemplification of what can be said in language, or as a way to dispel perplexities and illusions. ${ }^{5}$

Such uses certainly exist, and will be presented below; in the current article I wish to show that Wittgenstein's method goes beyond the forms noted above and reflects the philosophical change of direction he worked in the study of language. This revolution is based on the assertion that "essence is expressed by grammar" (Wittgenstein 2009, §371). In other words, all the modes of human thought are embodied in grammar. Grammar can act only as a regulator, because any one-time use cannot create meaning. In the Philosophical Investigations, this regulatory aspect finds expression in the dialogical nature, inasmuch as this is how our grammar is implemented in daily life: from buying red apples at the start of the book, through participation in various games, and concluding with the inquiry into internal processes and states such as intention and pain. The original contribution of the present article is its demonstration of the link between the type of dialogue and the human action taken, such that there is a substantive connection (in the sense of §371) between the dialogical grammar and the type of conscious/mental action.

Wittgenstein's method, viewed as "dialogical grammar," functions on two levels: the first includes the technical plane of punctuation signs that denote direct address, such as quotation marks, question marks, and exclamation points, all of which belong to the "surface grammar." The second level is that of

\footnotetext{
${ }^{1}$ I quote from the fourth, revised edition of the Philosophical Investigations (2009). In addition to the revision of the translation and reediting, there is another important innovation in this edition: the second part was re-edited and divided into sections. It is important to note that the title assigned to the second part, "Philosophy of Psychology: A Fragment," reflects a tendency that goes back to the 1980 s, and which grew stronger in the last decade, to focus on Wittgenstein's deliberate attention to the psychology of the individual as way to understand how language works. For our purposes here it is important to look at the place of individual psychology in the work and the existence of fruitful dialogue.

'For example, the editors write in the introduction to the 2009 edition: "We have also favoured colloquial compression, as in 'I'm', 'I'll', 'he'd', 'we'd', 'isn't', 'aren't', 'won't' and 'wouldn't', rather more than Anscombe, in order to bring out the conversational tone of the writing" (ibid., p. xiii).

${ }^{3}$ One of the major relevant works is Wittgenstein's Lectures on Philosophical Psychology 1946-1947, ed. P. Geach (Chicago: The University of Chicago Press, 1988), from which we will exemplify dialogical usage. See also his Lectures \& Conversations (Berkeley: University of California Press, 1966).

${ }^{4}$ Beth Savickey relates to Wittgenstein's manner of teaching and cites testimonies by his students that his lectures had the nature of meetings and lengthy conversations, and not of frontal instruction (Wittgenstein's Art of Investigation , pp. 58-59).

${ }^{5} \mathrm{~A}$ significant example of this is the scholarly reference to Wittgenstein's recurring discussion of the relationship between "picture" and "use." Marie McGinn, for instance, presents the awareness of the difference between picture and use as being conscious of the existence of a number of uses (Wittgenstein and the Philosophical Investigations, p. 85). In the current article, however, I will argue that this does not refer to a number of alternate uses, but to a dialogue between simultaneously functioning states of consciousness.
} 
the "depth grammar," which includes Wittgenstein's references to his sources of influence, whether explicit (Frege, Augustine, James, Plato) or implicit (conscious and unconscious, to which he was exposed in the context of his "form of life").

A second aspect that requires discussion of the connection between mode and content in the dialogical method is a series of auxiliary terms based on "dialogical consent" and which Wittgenstein coined as a way to understand how language works, such as "rule," "family resemblance," and "form of life." In an attempt to describe the nature of dialogue from a philological perspective, I will argue that Wittgenstein created a "strategy of understanding" in which the use of language is not based solely on technical capability or, alternatively, on some mystical ability, but also on mutual understanding that is expressed in agreement on definitions and judgments. ${ }^{6}$ The terms mentioned above have been intensively discussed in the scholarly literature; I do not intend to elaborate on them here, but only to argue that the dialogical nature of the Philosophical Investigations is the foundation for all of them. In his dialogue format, Wittgenstein delineated a triad (meaning-creature-understanding), each element of which participates in meaningful linguistic activity. This move is based on the need for justification, in certain conditions and circumstances, that always include a discourse (potential and not necessarily real) involving more than one person.

The present essay proceeds as follows: First, in light of the fact that Wittgenstein mentioned the Platonic dialogue form in the Investigations, we should begin by comparing the two men's forms of dialogue, especially in light of Wittgenstein's methodological directive to examine philosophical questions by a comparison of language-games. ${ }^{7}$ Here I will show that Wittgenstein had his reservations about Platonic dialogism, and then adumbrate three similarities between the two. In the second section, I will consider Wittgenstein's dialogical grammar in the Philosophical Investigations as comprising three species of grammar: rhetorical dialogue, conversational dialogue, and reflexive dialogue.

\section{The "Family Resemblance" between the Platonic Dialogue and Wittgenstein's Method}

\section{Wittgenstein's Criticism of Socrates}

Plato's dialogues have been the subject of extensive and variegated scholarly attention, with the emphasis on their division into three periods, each marked by dialogues of quite a different nature. An alternative interpretation of the periodization, relevant for a study of Wittgenstein, was advanced by Charles Kahn (1996), who proposed viewing the differences in the several types of dialogues as reflecting changes in Plato's position on various topics. ${ }^{8}$ There is a clear similarity between Kahn's interpretation of the role of dialogue in Plato's work and Wittgenstein's discussion, in the second part of the Investigations, of "changing aspect" (as will be exemplified below). First, however, we should examine the apparent differences between them.

On the few occasions that Wittgenstein used the term "dialogue," he did so to express his vigorous opposition to the Platonic form, both as a didactic and scholarly method and with reference to its content:

\footnotetext{
${ }^{6}$ As his unequivocal statement in the following paragraphs: "So you are saying that human agreement decides what is true and what is false?" - What is true or false is what human beings say; and it is in their language that human beings agree. This is agreement not in opinions, but rather in form of life. It is not only agreement in definitions, but also (odd as it may sound) agreement in judgments that is required for communication by means of language" (Philosophical Investigations, §§241-242).

${ }^{7}$ Wittgenstein, Philosophical Investigations, §130.

${ }^{8}$ Kahn presents Plato as critical of his own writings as he regards the significant change that occurred in Plato's dialogues as forgoing the pretension of imparting knowledge and teaching, in favor of the transition to the rhetoric of persuasion. See C. Kahn, Plato and the Socratic Dialogue (Cambridge: Cambridge University Press, 1996) pp. 376-377. This transition can be seen as paralleling that between the Tractatus and the Investigations.
} 
I can characterize my standpoint no better than by saying that it is the antithetical standpoint to the one occupied by Socrates in the Platonic dialogues. For if I were asked what knowledge is, I would enumerate instances of knowledge and add the words 'and similar things'. There is no shared constituent to be discovered in them since none exists. The traditional conception of the use of concept-words hangs together with the idea that the meaning of a word is something that must be present at the same time as meaningful use is made of the word. It is as if words were labels of bottles with particular contents, and if I take down the bottles, I thereby have my hands on the stated fluid contents as well. If it is objected that the words 'and similar things' do not give the concept a boundary, I can only say that the application of concept-words is in most cases actually not bounded. If one compares a concept, as Frege did, with an area in the plane, one could say that the use of a concept corresponds to an area with blurred boundaries ${ }^{9}$

Here Wittgenstein criticizes the Socratic notion of "forms" found in Plato's dialogues. He uses the metaphor of bottle and fluid to illustrate the perception of content as form and of its applications as fluid. Wittgenstein asserts that knowledge cannot be bounded; it is possible only to show its expressions. Hence no narrower concept can be bounded. It is possible only to show the various embodiments of any concept, but impossible to set its boundaries. The method that Frege had proposed is comparative and makes no attempt to arrive at essences. In effect, this is another formulation of the term "family resemblance" in the Investigations, or of Wittgenstein's critique in the Blue and Brown Books of the "craving for generality." 10

Wittgenstein was clearly opposed to the attempt, which he believed to be reflected in Plato's dialogues, to clarify the nature of things by means of the relation between a concept and its embodiment. This disagreement is implied in the very rejection of the dialogical method as a key to understanding or explanation. ${ }^{11}$

\section{The Similarities between Wittgensteinian and Socratic Dialogue: Quotation, Language as the Substrate for Thought, and Reflexive Dialogue}

At various junctures in the Investigations, Wittgenstein quotes the Theaetetus, demonstrating his acquaintance with complex conceptions of language in the Platonic dialogues. ${ }^{12}$ In $\S 46$, for example, he asks one of the fundamental questions that illuminate the transition from the Tractatus to the Investigations: "What lies behind the idea that names really signify simples?" In response, Wittgenstein quotes the Theaetetus, where Socrates asserts that primary elements cannot be defined (emphasis in the original). He goes on to quote Socrates' discussion of the boundaries of a name, which cannot determine if something exists or not, and therefore, in practice, "It is impossible to give an explanatory account of any primary element." ${ }^{3}$ At the end of the section, Wittgenstein compares Socrates' position to "Russell's 'individuals' and my 'objects' (Tractatus Logico-Philosophicus)." Then, in $\S 48$, he analyzes the action of calling by name and demonstrates its role in the language game of "representation." These sections can be seen as an expansion and exemplification of §43: giving names is one way to impart meaning, alongside others. This

\footnotetext{
${ }^{9}$ Wittgenstein, The Voices of Wittgenstein, pp. 33-34.

${ }^{10}$ Wittgenstein, Philosophical Investigations, §§66-67; L. Wittgenstein, The Blue and Brown Books (Oxford: Basil Blackwell, 1969), p. 17.

11"Reading the Socratic dialogues, one has the feeling: what a frightful waste of time! What's the point of these arguments that prove nothing and clarify nothing" (L. Wittgenstein, MS 111, 1931. The Collected Works of Ludwig Wittgenstein, Internet version [Oxford: Basil Blackwell; Charlottesville, VA : InteLex Corp., 1998] p. 55.

${ }^{12}$ Wittgenstein, Philosophical Investigations, $\S \S 46,48,518$. Maurice Drury quoted Wittgenstein, who claimed that "Plato in this dialogue is occupied with the same problems that I am writing about." See M. O. Drury, "Conversations with Wittgenstein," in Ludwig Wittgenstein: Personal Recollections, ed. R. Rhees, (Oxford: Basil Blackwell, 1981) p. 149.

${ }^{13}$ Wittgenstein, Philosophical Investigations, §46.
} 
does not mean that it is faulty, but only that it is part of a language game (just as the presentation of Augustine's stance on children's learning of language is not falsifiable, but only incomplete). ${ }^{14}$

In addition to Wittgenstein's direct quotations from Plato, which preserve the dialogue format, there are other similarities between the Greek philosopher's conception of language and Wittgenstein's study of language in the Investigations. I will show below how this family resemblance is a basis for understanding the importance of dialogue in the Investigations, not only as a method, but also as cognitive content, when Wittgenstein examines concurrent mental states. After looking at the types of dialogue in Investigations, I will propose the term "aspects-dialogue" for dialogue between two distinct mental states. The singularity of such dialogue lies in its inclusion of more than a single mental state by the same speaker; its use transforms the dialogical method into an expression of content and not only of manner.

\title{
Language as the Substrate of Thought
}

The dialogical conception of thought can be traced back to Socrates in the Theaetetus, where language is deemed to be the substrate of thought. ${ }^{15}$ Socrates depicts the thought process as grounded in an internal mental dialogue composed of questions and answers, affirmations and objections. This process continues until thought reaches something clear, whether as a result of the internal discourse or of a "leap." This internal process concludes when, whether gradually or suddenly, a person makes a statement that formulates a judgment. This statement is not intended for another person, nor is it formulated out loud:

\begin{abstract}
Socrates: A talk which the soul has with itself about the objects under its consideration. [...] The soul when it thinks is simply carrying on a discussion in which it asks itself questions and answers them itself, affirms and denies. And when it arrives at something definite, either by a gradual process or sudden leap, when it affirms one thing consistently and without divided counsel, we call this its judgment. [...] To judge is to make a statement, and a judgment is a statement which is not addressed to another person or spoken aloud, but silently addressed to oneself. ${ }^{16}$
\end{abstract}

Two points are important for our discussion: First, the dialogical process set forth here is not a matter of rhetoric (intended to persuade listeners that some assertion is correct), nor is it based on agreement between individuals. Second, formulation in language is a condition for the mental process. This silent verbalization is not intended for any communicative act, but only for the thinker's reflexive and internal activity. This reflexiveness can be compared to Wittgenstein's discussion of the will in Tractatus: A person can know his will. It is the will that gives meaning to the individual's world, making him happy or wretched; but he can formulate it only within the boundaries of his language and cannot influence facts that are expressed in language. ${ }^{17}$ Whereas Socrates presents this dialogical method as a response to the question of what thought is, for Wittgenstein in the Tractatus, reflexive thought has the nature of soliloquy. In the Investigations, by contrast, reflexive thought is clarified by means of dialogue. Soliloquy still exists, but

\footnotetext{
${ }^{14}$ In the Philosophical Investigations, $\$ 518$, Wittgenstein quotes an interchange from the Theaetetus that discusses the relation between image and picture and between "something" and "something real" as the starting point for proving the necessity of grammar for understanding through visual perception. Actually, Wittgenstein continues the Platonic dialogue in a formulation similar to that described above, with the dialogical method illustrating the process of clarification that exists within the context of the reality of a conversation between people, and not as theoretical thought. Savickey already indicated the methodological similarity between Investigations and the Platonic dialogues, in, for instance, examining the conduct of children to understand the use of language (Wittgenstein's Art of Investigation, p. 75).

${ }^{15}$ David Sedley used the phrase "Language as the Medium of Thought" as a subtitle for his discussion of "Plato on Language"; see "Plato on Language", in A Companion to Plato, ed. H. Benson (UK: Blackwell, 2009) pp. 214-227.

${ }^{16}$ Theaetetus, in Plato, Plato Complete Works, ed. John M. Cooper (Cambridge: Hackett PC, 1997) 189e-190a, p. 210.

17 "If the good or bad exercise of the will does alter the world, it can alter only the limits of the world, not the facts - not what can be expressed by means of language. In short the effect must be that it becomes an altogether different world. It must, so to speak, wax and wane as a whole. The world of the happy man is a different one from that of the unhappy man" (Wittgenstein, Tractatus, §6.43).
} 


\section{Dialogical Grammar}

Dorit Lemberger

takes place in universal language, which is not limited by the boundaries of a particular person. This view is stated concisely in the latter work: "A human being can encourage himself, give himself orders, obey, blame and punish himself; he can ask himself a question and answer it. So one could imagine human beings who spoke only in monologue, who accompanied their activities by talking to themselves."18

Wittgenstein concludes this discussion by denying the existence of some individual criterion that cannot be known by another person. At the same time, soliloquy is real, and its speaker uses "ordinary language." In other words, Socrates and Wittgenstein concur that even if the speaker chooses not to vocalize his thoughts, it is not because they cannot be expressed in universal language, but only because speaker opts to remain silent.

\section{Reflexive Dialogue: Simultaneous Sense-Perception and Image}

Now I want to show how a more complex cognitive reality is portrayed in the Philebus, which can be characterized as a dialogue between mental states. Socrates describes to Protarchus a situation in which different mental states appear concurrently and lead to the conclusion that there is more than one factor responsible for creating the content of thought. The dialogue between Socrates and Protarchus is completely rhetorical, but the content of what Socrates says refers to a form of mental dialogue that could obstruct judgment:

\footnotetext{
Socrates: If memory and perception concur with other impressions at a particular occasion, then they seem to me to inscribe words in our soul, as it were. And if what is written is true, then we form a true judgment and a true account of the matter. But if what our scribe writes is false, then the result will be the opposite of the truth. [...]

Socrates: Do you also accept that there is another craftsman at work in our soul at the same time? [...] A painter who follows the scribe and provides illustrations to his words in the soul.

Protarchus: How and when do we say he does this work?

Socrates: When a person takes his judgments and assertions directly from sight or any other sense-perception and then views the images he has formed inside himself, corresponding to those judgments and assertions. ${ }^{19}$
}

Below I will show how Wittgenstein related to this difficulty and resolved the tension. At this juncture, however, I want to conclude the comparison between the two dialogical methods, those of Socrates and Wittgenstein, by noting the similarity between their instructions for evaluating the meaning as a function of how a word is used, inasmuch as the same word can have multiple meanings. ${ }^{20}$ In both instances, dialogue functions as a method that enables both the use of the word itself and understanding it in relation to other possible uses. In the Euthydemus Plato shows how "learning" can be used to denote opposites, and strongly advises examining the manner in which the word is used in order to decide on its meaning (as does Wittgenstein in the Investigations, where the verb "use" appears in countless passages):

You must learn about the correct use of words. [...] You did not realize that people use the word 'learn' not only in which a person who has no knowledge of a thing in the beginning acquires it later, but also when he who has this knowledge already uses it to inspect the same thing, whether this is something spoken or something done. (As a matter of fact, people call the latter 'understand' rather than 'learn', but they do sometimes call it

\footnotetext{
${ }^{18}$ Wittgenstein, Philosophical Investigations, §243.

${ }^{19}$ Plato, Philebus 38c, p. 427.

${ }^{20}$ See Sedley, "Plato on Language" for an exhaustive examination of Plato's discussions on the nature of language, and particularly on equivocation.
} 
'learn' as well.) Now this, as they are pointing out, had escaped your notice - that the same word is applied to opposite sorts of men, to both the man who knows and the man who does not. ${ }^{21}$

The possibility of using the same word to denote two different things (for example, "learn" refers both to the acquisition of the previously unknown and to the acquisition of existing knowledge) requires that we conduct a meticulous examination of the specific use in order to determine meaning. We cannot make do with knowledge of the "inherent" meaning of a word, for even if a person knows every meaning of a word (as Socrates later argues), he cannot predict the nature of a certain use. The parallel to the concept of use in Investigations is clear: Wittgenstein, too, says that determination of the word's meaning must rest on the nature of its use, even if it seems to us there is some preexisting picture or experience. ${ }^{22}$

This parallel is supported by an additional argument, based on the considerable differences between human beings. In the Sophist, the visitor tells Theaetetus that, even if there is agreement on a particular name for something, each of them might view it differently. Consequently, the agreement concerning the essence of the matter must be stated explicitly; they cannot make do merely with agreement on the name. ${ }^{23}$ This view of the use of a word parallels Wittgenstein's argument that we must agree about definitions and judgments in order to conduct hold fruitful communications. ${ }^{24}$

To sum up, there is a series of parallels between the Socratic dialogues and the concept of language in the Investigations, reflected in dialogical grammar. These parallels sharing an inherent linkage between grammar and everyday life: language reflects human conduct, which is dynamic, cannot be defined on the basis of "quantitative scientific knowledge," and, in particular, is dialogical and based on agreement.

\title{
Dialogical Grammar: Rhetorical Dialogue, Conversational Dialogue, and Reflexive Dialogue in the Investigations
}

\author{
Dialogism in the Investigations: The View from Above ${ }^{25}$
}

Almost the whole time I am writing conversations with myself. Things I say to myself tête-à-tête. ${ }^{26}$

Although the dialogical method of the Investigations is unmistakable, Wittgenstein scholarship relates to it infrequently and emphasizes the rhetorical impact of dialogue to persuade us of Wittgenstein's unequivocal stance on central issues, such as the possibility of private language or second sense. ${ }^{27}$ Here

\footnotetext{
${ }^{21}$ Plato, Euthydemus 277e-278c, pp. 714-15.

${ }^{22}$ See, e.g., Wittgenstein, Philosophical Investigations, §59 and many others.

${ }^{23}$ Plato, Sophist $218 \mathrm{c}-\mathrm{d}$, p. 238.

24“'So you are saying that human agreement decides what is true and what is false?' What is true or false is what human beings say; and it is in their language that human beings agree. It is not only agreement in definitions, but also (odd as it may sound) agreement in judgments that is required for communication by means of language" (Wittgenstein, Philosophical Investigations, §§241-242).

${ }^{25}$ “ $\mathrm{A}$ surveyable representation produces precisely that kind of understanding which consists in 'seeing connections'. Hence the importance of finding and inventing intermediate links" (Wittgenstein 2009, §122).

${ }^{26} \mathrm{~L}$. Wittgenstein, Culture and Value (Oxford: Blackwell, 1980), p. 88.

${ }^{27}$ A prevalent contemporary scholarly view relates to dialogue only incidentally, within other discussions, as, for example, in the context of private language when dialogue is harnessed in support of the position attributed to Wittgenstein (M. McGinn, Wittgenstein and the Philosophical Investigations, pp. 134-135.). Even in works that give pride of place to interpersonal discussions, as Wittgenstein and the Possibility of Discourse (Rhees 1998), that describe dialogue as essential, not only as a expression of control of the technique of language, but also for understanding the nature of the discussion, the nature of dialogue is shunted aside in favor of the underlying clarification of the way in which what is understood is distinguished from what is not (McGinn, Wittgenstein and the Philosophical Investigations, pp. 90-91). In the final analysis, we conclude that speaking in language does not always entail discussion (ibid, p. 94).
} 
I would like to consider the dialogue for its own sake, with its various aspects, while applying Wittgenstein's methodological directive on "finding and inventing intermediate links."

Actually, when Wittgenstein uses the word "dialogue," he generally is critical of Plato's use of the format (as in the passage from Voices of Wittgenstein quoted earlier). But when he described his conversations with his friends, or routine communicative acts between people, he uses the words Gesprach, Gesprachen (conversation). In practice, Wittgenstein regarded conversation as a central medium of human activity and as the key to understanding our use of language. ${ }^{28}$ When he referred to the regulated conduct of a conversation, in which it seems to us that the listener perceives the meaning of what is said by the encounter with the manner in which he perceives this meaning in his own mind, Wittgenstein turned a routine everyday activity (the language-game of reporting) into something unfamiliar. He did this in order to argue that the process of conveying meaning in a conversation is complex and its success not to be taken for granted. Notwithstanding, this language-game reflects the fact that speech, conversation, is the "straight highway" for the transmission of meaning between two people.

The German word that Wittgenstein used in the above passage, Selbstgespräche ("conversations with myself") illustrates, without irony or any rhetorical interest, the nature of the Wittgensteinian dialogue in the Investigations. He was in the habit of writing his works as if they were private conversations with himself. Wittgenstein's reflexive awareness of the manner of his writing did not prevent him from classifying it as the key to understanding his future activity; that is, he did not assign precedence to what is said in the first person when someone is speaking to himself. ${ }^{29}$ All the same, he applied this dialogical method in the Investigations in a way that sometime makes it difficult to determine whether he is documenting an internal dialogue or one with another person. In any event, my use of the term "dialogical grammar" is meant to assert that Wittgenstein's depth-grammar incorporates a set of rules that are based in dialogue: the contextgrounded conversation between (at least) two principals, mutual recognition (by one agent of the other), and agreement regarding its regulatory nature. ${ }^{30}$ On the surface-grammar level, these rules are sometimes invisible or only alluded to, but in any event they allow us to base the discussion on them, as was noted by Jane Heal. ${ }^{31}$ The use of dialogical grammar, even if readers face it on their own, entails giving up unequivocal conclusions, as well as a constant movement between one aspect and another, in the attempt to clarify the connections between mental processes and the language in which they are fashioned.

The dissimilarity between the forms of argumentation in the Tractatus and in the Investigations is already evident from a comparison of their respective introductions. In the Tractatus Wittgenstein argues, "The truth of the thoughts that are here communicated seems to me unassailable and definitive."32 In his

\footnotetext{
28 "What is the language-game of communicating something? l'd like to say: you regard it too much as a matter of course that one can communicate anything to anyone. That is to say, we are so much accustomed to communicating in speech, in conversation, that it looks to us as if the whole point of communicating lay in this: that someone else grasps the sense of my words - which is something mental - that he, as it were, takes it into his own mind. If he then does something further with it as well, that is no part of the immediate purpose of language" (Wittgenstein, Philosophical Investigations, §363).

${ }_{29}$ The following passage is an important example of this:

At the question "Why don't I infer my probable actions from my talk?" one might say that it is like this: as an official in a ministry I don't infer the ministry's probable decisions from the official utterances, since of course I am acquainted with the source, the genesis of these utterances and of the decisions. -- This case would be comparable to one in which I carry on conversations with myself, perhaps even in writing, which lead me to my utterances out loud in conversation with other people; and now I say: I shall surely infer my future behavior, not from these utterances, but from the far more reliable documents of my inner life. (Wittgenstein, Culture and Value, §711). ${ }^{30}$ See Wittgenstein, Philosophical Investigations, $\$ \S 664$. Gordon Baker already pinpointed the connection between depth-grammar and the form of life which conditions its overall understanding. See G. Baker, "Wittgenstein's 'Depth Grammar'” Language \& Communication 21 (2001) pp. 303-19.

31 "The fact that the dialogue element in the Investigations is introduced so inexplicitly and is not signposted by some uniform devise enables Wittgenstein to foreground it or background it to the extent that seems most appropriate to him at any given stage of the discussion" (J. Heal, "Wittgenstein and Dialogue," in Timothy Smiley, ed., Philosophical Dialogues (Oxford: Oxford University Press, 1995) p. 72.

${ }^{32}$ L. Wittgenstein, Tractatus Logico-Philosophicus (London: Routledge, 1961) p. 24.
} 
introduction to the Investigations, by contrast, he presents the book as an album that evades the possibility of pointing in a single coherent and clear direction. ${ }^{33}$ Furthermore, the presence of an interlocutor is emphasized in the latter, both formally and rhetorically. On the formal level, many sections in the book raise or answer a question. On the rhetorical level, this produces a conversation. Whereas Wittgenstein's statements in the Tractatus are formulated as logical propositions, in an unequivocal and declarative tone that brooks no dispute, only rarely do we find in the Investigations emphatic claims that do not lead into a renewed discussion. To this we should add Wittgenstein's methodological directives to avoid definitions and to accept the impossibility of unequivocal definitions (and therefore we must make do with indicating the "family resemblance" between things). I will attempt to show how the dialogical method suits Wittgenstein's arguments, building on his assertion that there is no difference between method and content, because there is no "second-order language." ${ }^{34}$ At the same time, however, I wish to demonstrate how we nevertheless can distinguish between the various ways of language use that represent different ways in which language functions, pursuing Wittgenstein's argument that language functions in different ways. ${ }^{35}$ From a methodological perspective, this differentiation between ways of usage is made possible by the dialogue, which facilitates the emergence of a distinct intersubjective process that is not subservient to some other or prior order. This illustrates how language enables the expression of a singular encounter between two agents, one that is not amenable to generalization, definition, or standardization. There are many types of duality: two people, two aspects in the experience of a conflict by a certain person or by the two parties. In any event, in some instances we can speak of duality that is regulative and not a one-time occurrence and that cannot be reduced to an unequivocal description.

I have chosen to demonstrate this with three aspects that appear more than others and that concretely illustrate the function of the dialogical method. These aspects are part of a broader array of differences between the language of the Tractatus and that of the Investigations.

\section{Aspects of Dialogism}

The first prominent aspect is the technical and rhetorical, which Wittgenstein often uses to present the recurrent arguments in the Investigations, such as the need to examine meaning in the context of use, the inherent connection between language and everyday actions, and the avoidance of theories and second-order language. The second aspect relates to instances in which Wittgenstein mentions, either directly or incidentally, his interlocutor-colleagues, such as Frege and Ramsey, and interlocutorpredecessors, such as Plato, Augustine, and William James. The third, reflexive aspect, refers to dialogue between mental states. In my survey of this aspect I will attempt to show how, even when Wittgenstein finally decides in one direction or another, the dialogue method reflects the possible existence of two parallel states, even if these are two concurrent mental states. Our review above of the characteristics of the Socratic dialogical method enables us to see their great similarity to Wittgensteinian dialogue, more than Wittgenstein and his readers were aware.

\section{Dialogue as Technique}

The dialogue format of most of the Investigations and of many passages in Wittgenstein's posthumous works is at the center of the affinity between Platonic and Wittgensteinian dialogue. Furthermore, both Plato and Wittgenstein are most apt to employ dialogue to clarify common terms or

\footnotetext{
33 "My thoughts soon grew feeble if I tried to force them along a single track against their natural inclination, And this was, of course, connected with the very nature of the investigation. For it compels us to travel criss-cross in every direction over a wide field of thought. [...] So this book is really just an album" (Wittgenstein, Philosophical Investigations, §3-4).

${ }^{34}$ Ibid., §121.

35 "The paradox disappears only if we make a radical break with the idea that language always functions in one way, always serves the same purpose: to convey thoughts which may be about houses, pains, good and evil, or whatever" (ibid., §304).
} 
conceptions; dialogue functions as a technique to discard an illusion about the nature of language. In Wittgenstein's first use of Technik, in the sense of the rules of a game, he argues that even though we establish a "technique," we are still not able to control the course of the game. ${ }^{36}$ The result is a contradiction between what we expected would happen and what actually took place; consequently, we say: "That's not the way I meant it." ${ }^{37}$ On the level of surface grammar, except for the sentence enclosed in quotation marks (as in a conversation), the dialogical grammar is expressed in the recurring use of the first-person plural. This creates the sensation that all the readers are participating in a joint activity and that they all sense the contradiction between the individual intention and the action in the game. On the depth-grammar level, Wittgenstein offers the ultimate example of tension in a dialogical context, when there is a difference or contradiction between the speaker's intention and his action in the shared language. In §664, Wittgenstein returns to the example of intention in order to illustrate the role of depth grammar and emphasizes the gulf between the two types of grammar that emerges in dialogue, between a person's words when speaking to himself and the adherence to conventional rules in actual speech. The dialogue between the two uses is expressed in actual speech and preserves the possibility of distinguishing between depth and surface grammar (ibid.).

Wittgenstein's depiction of the attempt to distinguish between fantasy and reality is an outstanding example of the function of dialogue as technique. This is a rare instance of Wittgenstein's use of the word "dialogue" to denote an effective method and not to criticize Plato. Along with the use of dialogical grammar on the surface level (questions, quotations), Wittgenstein wrote dialogue as a technique for exploring the nature of his thought action. As I argued above, dialogue functions as an imaginary technique that allows us to determine whether the speaker is fantasizing or not. 38

This passage also embodies two additional functions of dialogue. One is the internal dialogue between the dreamer and himself, which Wittgenstein presents as "quite imaginable"; the other, the "dialogue of a play," reveals the possibility of a gulf between language games. In dramatic dialogue, the playwright is not giving expression to his own intention, but to that of the character on stage. Whereas the internal dialogue of a dream does not employ any specific technique, dramatic dialogue exemplifies dialogue as a conventional technique in a literary-artistic language game. Dialogue serves a similar function for clarifying a series of "problems and disquietudes." 39 Following Augustine, Wittgenstein argues that it is in fact the simple things that are hidden from sight. ${ }^{40}$ As in Platonic dialogue, Wittgensteinian dialogue works a defamiliarization that makes it possible to examine the simple things, inasmuch as dialogical grammar contains direct address and the asking of questions, techniques that require a reexamination of the instinctive manner in which we generally act in language. Dialogue as a technique is not only a rhetorical means, but also a psychological one (in the Wittgensteinian sense, in which psychological terms help distinguish among different uses of language). By means of dialogue, a person may extricate himself from a linguistic move that seems necessary when communicating with himself, and correctly understand it by

\footnotetext{
36"Here the fundamental fact is that we lay down rules, a technique, for playing a game, and that then, when we follow the rules, things don't turn out as we had assumed. So that we are, as it were, entangled in our own rules. This entanglement in our rules is what we want to understand: that is, to survey. It throws light on our concept of meaning something. For in those cases, things turn out otherwise than what we had meant, foreseen. [...] That is just what we say when, for example, a contradiction appears: 'That's not the way I meant it.' The civic status of a contradiction, or its status in civic life - that is the philosophical problem" (ibid., §125).

${ }^{37}$ Ibid.

38“"Suppose it were part of my day-dream to say: 'I am merely engaged in phantasy', would this be true? Suppose I write such a phantasy or narrative, an imaginary dialogue, and in it I say 'I am engaged in phantasy' -- but, when I write it down, -- how does it come out that these words belong to the phantasy and that I have not emerged from the phantasy? Might it not actually happen that a dreamer, as it were emerging from the dream, said in his sleep 'I am dreaming'? It is quite imaginable that there should be such a language-game. This hangs together with the problem of 'meaning'. For I can write 'I am healthy' in the dialogue of a play, and so not mean it, although it is true. The words belong to this and not that language-game" (L. Wittgenstein, Zettel, ed. G. H. Von Wright, and E. M. Anscombe (Oxford: Basil Blackwell, 1981, §397).

${ }^{39}$ Wittgenstein, Philosophical Investigations, §111.

${ }^{40} \mathrm{lbid}$, $§ 90$.
} 
means of "external criteria" that make this possible. ${ }^{41}$ At times, however, dialogue with a real interlocutor is required to elucidate a particular insight.

\section{Conversational Dialogue}

Throughout his philosophical career, starting from its beginning, Wittgenstein regularly engaged in conversations and correspondence, at first with his teachers, Frege and Russell, and later with his students and colleagues. ${ }^{42} \mathrm{He}$ mentioned these dialogues in various contexts, and in the Investigations, in the formulation of specific arguments. To this we should add evidence of the clear influence of thinkers to whom he referred (Kierkegaard) or whom he quoted (James, Augustine). Whether or not Wittgenstein agreed with them on a specific point, we can see the very allusion or quotation as evidence that he saw their argument as a challenge worthy of attention and response. ${ }^{43}$ His dialogue with Frege is an outstanding example of this. On the one hand, Wittgenstein disputes Frege's claim that assertability is tantamount to a move in the language-game. ${ }^{44}$ In another place, though, he agrees with Frege that a name alone has no meaning outside a sentence. ${ }^{45}$

"Dialogical grammar" means that dialogue is conducted as conversation with another philosopher (real or virtual), colleague, or student-colleague. In this "conversation," Wittgenstein disputes his interlocutor's position or question, because doing so makes it possible to clarify a problem in understanding a language-act. In the Investigations, when Wittgenstein mentions Augustine, Frege, or James, he does not present him as a thinker who merely brought the issue to his own awareness, but as one who was engaged with this matter and coined an expression (such as James's "if-feeling") or originated a common insight (such as learning by ostensive definition, as in Augustine). So the scholarly consensus that Wittgenstein was not actually influenced by his interactions with other thinkers, but merely used their statements to justify his own stance, is not surprising. ${ }^{46}$ Since, however, Wittgenstein himself wrote the Investigations in dialogue format, interspersing these philosophers' statements into his text, this question should be reexamined.

\footnotetext{
${ }^{41}$ lbid, $\$ 580$.

42 In the introduction to the Tractatus, Wittgenstein seemingly negated the importance of finding the sources of intellectual inspiration for what he wrote. In the introduction to the Investigations, in contrast, he makes the ability to understand the problems in the former, as well as the stimulus and clarification at the basis of the book, conditional upon his conversations with his colleagues Ramsey and Sraffa: "For since I began to occupy myself with philosophy again, sixteen years ago, I could not but recognize grave mistakes in what I set out in that first book. I was helped to realize these mistakes to a degree which I myself am hardly able to estimate - by the criticism which my ideas encountered from Frank Ramsey, with whom I discussed them in innumerable conversations during the last two years of his life. Even more that to this - always powerful and assured a criticism, I am indebted to that which a teacher of this university, Mr P. Sraffa, for many years unceasingly applied to my thoughts. It is to this stimulus that I owe the most fruitful ideas of this book" (Wittgenstein, Philosophical Investigations, 4). See also ibid, §81 n.

${ }^{43}$ Russell Goodman already suggested this interpretation, and offered a comprehensive examination of Wittgenstein's dialogue with James. His position, however, is not representative of most scholarly opinion; see R. Goodman, Wittgenstein and William James (Cambridge: Cambridge University Press, 2004).

44 "Frege's opinion that every assertion contains an assumption, which is the thing that is asserted, really rests on the possibility, found in our language, of writing every assertoric sentence in the form 'It is asserted that such-and-such is the case'. But 'that such-andsuch is the case' is not a sentence in our language - it is not yet a move in the language-game" (Wittgenstein, Philosophical Investigations, §22; emphasis in the original).

45 "With the mere naming of a thing, nothing has yet been done. Nor has it a name except in a game. This was what Frege meant too when he said that a word has meaning only in the context of a sentence" (ibid., §49).

46"Wittgenstein rarely quotes other authors and when he does so, he brings attention to where he differs rather than where he agrees with them" (Todor Polimenov, "Wittgenstein in Conversation with His Sources: Anspielungen und Zitate im Werk Ludwig Wittgensteins by H. Biesenbach," Nordic Wittgenstein Review 1 [2012] p. 200). See also Henry Jackman's thorough discussion and conclusion: "In conclusion, in spite of the fact that James was one of the most frequently cited authors in the Investigations, he was not one [sic] 'a classical opponent of the tradition in the philosophy of mind that [Wittgenstein] was opposing.' There remain, of course, serious differences between the two philosophers, but in terms of what was central to their outlook, Wittgenstein and James were far less apart than has been commonly assumed" (H. Jackman, "Wittgenstein and James's 'Stream of Thought," Meeting of the Society for the Advancement of American Philosophy (2004) p. 9; the internal quotation is from Coope et al, A Wittgenstein Workbook (Oxford: Blackwell, 1970) p. 7.
} 
In contrast to this consensus, I maintain that in the Investigations and other late works, as earlier in his Vienna Circle period, Wittgenstein frequently referred to other positions, not only to dispute them or for rhetorical purposes, but also as a catalyst for a more precise formulation of his arguments, or as a source for key questions that require attention. The fact that Wittgenstein rarely expressed complete agreement with his interlocutor does not detract from the importance of the conversation. In this sense, there is a marked resemblance to the Platonic dialogues, each of which is named for Socrates' main interlocutor in it. This "other speaker," whether fictitious, a stand-in for Plato himself, or a real person, fulfills a similar function: revealing (generally dialectically) the various facets of the discussion, which usually does not arrive at an unequivocal definition of a concept, even if consensus is reached. ${ }^{47}$

Another example of conversational dialogue can be found in dialogues that were not edited by Wittgenstein, in the collected lectures on psychological concepts that record mainly exchanges between Wittgenstein and his students. ${ }^{48}$ There Wittgenstein begins his attempt to describe "motive," as opposed to "reason," with the reservation that we cannot automatically assume that all humans learn and know how to use all language-games. Nevertheless, in the context of the description of a motive or reason for an action, a person elucidates, not only for himself but also for those around him, why he performed that action. ${ }^{49} \mathrm{~A}$ reason is given or a factor described in dialogical fashion, since, at least in this conversation, a person does not have to explain to himself why he performed a certain act, but only to another. A linguistic-ethical discussion derives from this question, since Malcolm suggests that if a person offers an absurd reason for committing murder, it cannot be defined as a motive. Intriguingly, Wittgenstein himself, as a teacher, struggles with the question of when different terms should be used to describe the background for a certain action ("It's not clear to me") ${ }^{50}$ and, in particular, how his students' questions lead him to the cardinal distinction between the reason for an action and the motive behind it. As regards the former, a person can explain to himself the connection between two moves (for instance, I stay in my job because I need money). ${ }^{51}$ As for the latter, Wittgenstein draws a parallel between the murderer's explanation and a bull's response to a red flag: the connection between the facts is evident, but cannot be justified ethically or causally by the person; rather, it "just happens."

\section{Reflexive Dialogue}

Reflexive dialogue is the third type of dialogue, and is the most complex and vaguest of the three types presented here. This is because it is mixed with dialogues of other types and because it includes internal dialogue that is shaped by the criteria of public speech so that it will be comprehensible to others. The choice to keep this dialogue an internal monologue derives from a need for privacy, embarrassment, or shame, but not from a linguistic deficiency. ${ }^{52}$ Language functions as a mechanism that enables reflection, self-examination, and self-knowledge. In the Investigations, Wittgenstein frequently employs dialogue to

\footnotetext{
${ }^{47}$ This position is represented, e.g., by Sedley, who divided the Platonic dialogues into periods, with the later dialogues characterized by discourse lacking unequivocal answers/definitions (Sedley, "Plato on Language"). See also Scolnicov on Plato's two different perceptions of language that create an open, skeptical, and reserved dialogical language (S. Scolnicov Idea and Method, Thirty-Three Studies in Plato (Hebrew) (Jerusalem: Magnes Press, 2008) pp. 301-307.

${ }^{48}$ Wittgenstein, Lectures on Philosophical Psychology 1946-1947.

49lbid, pp. 82-84.

${ }^{50}$ lbid, p. 3.

${ }^{51}$ Ibid.

${ }^{52}$ In his discussion of Wittgenstein's notion of private language, Norman Malcolm coined the term "contingent private language" (N. Malcolm, "Wittgenstein's Philosophical Investigations," Philosophical Review 62 [1954], pp. 530-559). This means that a person can conduct a conversation that, for various reasons, is wholly inner, and therefore his language seems private (but it is possible that other people will understand what is said in this conversation if the speaker chooses to include them). Such use of language ensues from the need for privacy, and Wittgenstein himself exemplified this when he wrote "secret diaries" while a prisoner of war during the First World War.
} 
describe self-observation (Selbstbeobachtung aussprechen); for example, when the speaker portrays longing and expectation, which he experiences as an inner process:

"I've heard he is coming; I've been expecting him all day." This is a report on how I have spent the day. In conversation, I come to the conclusion that a particular event is to be expected, and I draw this conclusion in the words "So now I must expect him to come." This may be called the first thought, the first act, of this expectation.

The exclamation "I'm expecting him - I'm longing to see him!" may be called an act of expecting. But I can utter the same words as the result of self-observation, and then they might amount to: "So, after all that has happened, I'm still expecting him with longing." It all depends on what led up to these words ${ }^{53}$

This passage graphically illustrates the role of dialogue, since Wittgenstein lists both the surfacegrammar depth-grammar roles, thereby shedding light on the use of Selbstbeobachtung. Wittgenstein points to the process that occurs on the surface level in the speaker's mind, in the description of the transition from expression to conclusion, as these take place "in conversation" in the individual's mind. He then distinguishes "first thought" from "exclamation" that expresses "an act of expecting." Here we have two types of "self-observation." The first watches the actions of language-reporting, conversation, contemplation, and expectation. The second is self-observation that also directed to a certain conclusion beyond the distinction between the language-acts. The conclusion includes a sort of self-criticism ("After all that has happened, I'm still expecting him with longing"). Wittgenstein next seeks to clarify the nature of "the process of introspection." This process functions as a reconstruction of past states of consciousness, and differs from self-observation in the present. It is noteworthy that Wittgenstein uses dialogical language only in relation to the present (and not to the past) to depict a situation of indecision followed by a decision. ${ }^{54}$

An additional example of introspective activity formulated in dialogical grammar is when selfobservation makes it possible to distinguish between levels of intention:

\footnotetext{
"When you were swearing just now, did you really mean it?" This amounts to something like: "Were you really angry?" And the answer may be given on the basis of introspection, and is often some such thing as "I didn't mean it very seriously," "I meant it half jokingly," and so on. There are differences of degree here. ${ }^{55}$
}

Self-observation makes it possible to detect differences of degree in the speaker's intention, drawing on the inner dialogue in which the speaker clarifies the seriousness of his intent.

Wittgenstein's discussions of memory constitute an additional example of an internal dialogue in which two states are compared. Wittgenstein does not explicitly refer to the Meno, in which Socrates portrays search and learning as recollection, dependent on a person's courage and continual quest, but we can see the similarity. ${ }^{56}$ These three actions-searching, learning, and recollection-are characteristic of Wittgenstein's inquiry about the characteristics of the inner processes in which memory takes part. ${ }^{57}$ In this context he also raises the need for an external criterion to bear witness to an action of memory; at the same time, "we bear in mind" the model we select to determine whether we remember it. That is, there is a

\footnotetext{
${ }^{53}$ Wittgenstein, Philosophical Investigations, §586.

${ }^{54}$ Ibid., §588.

${ }^{55}$ Ibid., $\$ 677$.

${ }^{56}$ Plato, Meno 81c-d.

${ }^{57}$ See, e.g., Wittgenstein, Philosophical Investigations, §§53, 56, 166.
} 
reflexive dialogue between the remembered model and a specific use in the present, such as the attribution of a certain color to an object. ${ }^{58}$

An additional point of similarity between the account of recollection in the Meno and Wittgenstein's description of inner processes is found in his argument that an individual process is based on a potential mental mechanism that can be detected only when an action is conducted in general, public language. Socrates' claim that "the soul has learned everything," and that a person can consequently recall specific things when he learns them, is analogous to Wittgenstein's argument that the action of the pedal is based on the existence of an entire mechanism, which, although concealed, is necessary for a concrete action to take place. ${ }^{59}$ Moreover, this context, too, is identical to that in Meno: Wittgenstein uses the metaphor of pedal and mechanism in order to depict a process of learning by ostensive definition. ${ }^{60}$

A completely different type of mutual dialogical interaction that is reflected in the use of language in the speaker's mind can be found in the Notebooks 1914-1916, and in parallel assertions in the Tractatus. ${ }^{61}$ These works incorporate mental dialogue of two types: the first, dialogue between what exists within the bounds of language and what definitely exists, but beyond the bounds of language (and the world); 62 the second, the dialogue between what is said and what is shown and cannot be explicitly expressed. ${ }^{63}$ A sentence in language does not express the rules of syntax that make its formulation possible, but reflects them by expressing a meaning.

Here we can distinguish between two rule types that are constitutive for the use of language: normative-consensus rules, and logical rules that are independent of human consent. ${ }^{64}$ Once again we are speaking of reflexive dialogue in which a person makes decisions in the realms of ethics, aesthetics, and belief, although, according to Wittgenstein, these decisions cannot be justified on a factual basis and therefore cannot be justified in general language. But instead of remaining silent, as Wittgenstein prescribes at the end of the Tractatus, we could say that conscious decisions in these realms require a reflexive dialogue in which the various possibilities are examined.

\section{Conclusion}

In this article I have looked at the explicit and implicit characteristics of Wittgensteinian dialogue. I have tried to show how Wittgenstein was influenced by the Dialogues of Plato which, despite his reservations about them, have many similarities with his own dialogues. This resemblance was one of the underpinnings of Wittgenstein's method in the Philosophical Investigations. He employed this foundation to dispel the perplexities produced by incorrect use of language. To achieve this, he employed a dialogical method that copes with the questions and problems associated with human beings' use of language in their actions and does not rest content with a theoretical examination. Because these problems fall into different

\footnotetext{
${ }^{58} \mathrm{lbid}, \S 56$.

59 'II set the brake up by connecting rod and lever' - Yes, given the whole of the rest of the mechanism. Only in conjunction with that is it a brake-lever, and separated from its support it is not even a lever; it may be anything, or nothing" (Wittgenstein, Philosophical Investigations, §6).

60 lbid., §6.

${ }^{61}$ L. Wittgenstein, Notebooks 1914-1916, ed. G. H. Von Wright and E. M. Anscombe, $2^{\text {nd }}$ ed. (Oxford: Basil Blackwell, 1979).

${ }^{62}$ lbid, pp. 72-73.

63"Propositions cannot represent logical form: it is mirrored in them. What finds its reflection in language, language cannot represent. What expresses itself in language, we cannot express by means of language. Propositions show the logical form of reality. They display it [...] What can be shown, cannot be said" (Wittgenstein, Tractatus, §§4.121, 4.1212).

${ }^{64}$ Wittgenstein's statement: "Grammar is not accountable to any reality" demonstrates the claim for the independence of language; See: L. Wittgenstein, The Big Typescript: TS 213. G. Luckhardt and M. A. E. Au (eds. and trans.) (Oxford: Blackwell, 2005) p. 85.
} 
categories, they must be addressed by different forms of dialogue. I have defined three such, which respond to the various needs linked to the use of language.

In conclusion, Wittgenstein's dialogical notion of language can be illustrated as an anthropomorphization of words, giving them a face that looks at us and seems to request a response, like the face in a painting. Continuing in this vein, a proposition creates a "group portrait." Nevertheless, the existence of agents who can engage in dialogue does not eliminate the question of how meaning comes into existence; instead, it rather directs our attention to the boundaries within which meaning is created:

While any word - one would like to say - may have a different character in different contexts, all the same there is one character - a face - that it always has. It looks at us. - For one might actually think that each word was a little face; the written sign might be a face. And one might also imagine that the whole proposition was a kind of group-picture, so that the gaze of the faces all together produced a relationship among them and so the whole made a significant group. But what constitutes the experience of a group's being significant? And would it would be necessary, if one is to use the proposition, that one feel it as significant in this way? ${ }^{65}$

\section{Works Cited}

Baker, Gordon. “Wittgenstein's 'depth grammar'.” Language \& Communication 21 (2001): 303-319.

Dascal, Marcelo. “Introduction," in: Dialogue: An interdisciplinary approach, ed. Marcelo Dascal, John Benjamin Publishing company, 1985, pp. 1-9.

Drury, Maurice O. 'Conversations with Wittgenstein', in Ludwig Wittgenstein: Personal Recollections. Ed. Rush Rhees. Oxford: Basil Blackwell, 1981.

Goodman, Russell. Wittgenstein and William James. Cambridge: Cambridge UP, 2004.

Heal, Jane. "Wittgenstein and Dialogue" Ed. Timothy Smiley, Philosophical Dialogues. Oxford: Oxford UP, 1995. 63-83.

Jackman, Henry. 'Wittgenstein \& James's "Stream of Thought"'. Meeting of the Society for the Advancement of American Philosophy (2004):1-9.

Kahn, Charles. Plato and the Socratic Dialogue. Cambridge: Cambridge UP, 1996.

Keightley, Alan. Wittgenstein, Grammar and God. London: Epworth Press, 1976.

Malcolm, Norman (1958). Ludwig Wittgenstein: A Memoir. Oxford: Oxford UP, 2001.

McGinn, Marie. Wittgenstein and the Philosophical Investigations. London: Routledge, 1997.

Parret, Herman. "Contexts as constraints on understanding in dialogue". In: Dascal, Marcelo (ed.), Dialogue: An interdisciplinary approach. 1985, pp. 165-179

Plato. Plato Complete Works. Ed. John M. Cooper. Cambridge: Hackett PC, 1997.

Polimenov, Todor. "Wittgenstein in Conversation with His Sources: Anspielungen und Zitate im Werk Ludwig Wittgensteins by H. Biesenbach." Nordic Wittgenstein Review 1 (2012): 200-208.

Rhees, Rush. Wittgenstein and the Possibility of Discourse. Ed. Dewey Z. Phillips. Cambridge: Cambridge UP, 1998.

${ }^{65}$ L. Wittgenstein, Culture and Value, $\$ 322$. 
Savickey, Beth. Wittgenstein's Art of Investigation. London: Routledge, 1999.

Sedley, David. "Plato on language." Ed. Benson, Hugh. H. A Companion to Plato. UK: Blackwell, 2009. 214-227.

Scolnicov, Samuel. Idea and Method, Thirty-three Studies in Plato. (in Hebrew). Jerusalem: Magnes, 2008.

Ter-Hark, Michel. "Wittgenstein on the Experience of Meaning and Secondary Use." Eds. O. Kuusela and M. McGinn, eds. 2011. The Oxford Handbook of Wittgenstein. Oxford: Oxford University Press, $\mathrm{pp}$

Wittgenstein, Ludwig. (1922). Tractatus Logico-Philosophicus. New-York: Routledge \& Kegan Paul (2 ${ }^{\text {nd }}$ edition), 1961.

Wittgenstein, Ludwig. MS 111, 1931. The Collected Works of Ludwig Wittgenstein, Internet version, Oxford: Basil Blackwell Pub.

L Lectures \& Conversations. Berkeley: University of California Press, 1966.

The Blue and Brown Books .2nd ed. Oxford: Basil Blackwell, 1969.

Notebooks 1914-1916. Eds. Von Wright, George H. and Elizabeth M. Anscombe. $2^{\text {nd }}$ ed. Oxford: Basil Blackwell, 1979.

Remarks on the Philosophy of Psychology, vol. I. Eds. Von Wright, George H. and Elizabeth M. Anscombe. Trans. G. E. M. Anscombe. Oxford: Basil Blackwell, 1980.

(1967). Zettel. Eds. Von Wright, George H. and Elizabeth M. Anscombe. Oxford: Basil Blackwell, 1981.

Lectures on Philosophical Psychology 1946-1947, (Ed. Peter Geach), Chicago: The University of Chicago Press, 1988.

_ Culture and Value, trans. Peter Winch, $2^{\text {nd }}$ ed., Oxford: Basil Blackwell, 1998.

- The Voices of Wittgenstein. Trans. Baker, Gordon, Michael Mackert, John Connolly and Vasilis Politis. London: Routledge, 2003.

- The Big Typescript 213. Eds. and trans: Grant Luckhardt and Maximilian Aue. Oxford: Blackwell publishing, 2005.

Philosophical Investigations, $4^{\text {th }}$ ed. Trans. Anscombe, Elizabeth M., Peter Hacker and Joachim Schulte; Eds. Peter Hacker, Joachim Schulte. UK: Wiley-Blackwell, 2009.

\section{(cc) EY}

New articles in this journal are licensed under a Creative Commons Attribution 4.0 United States License.

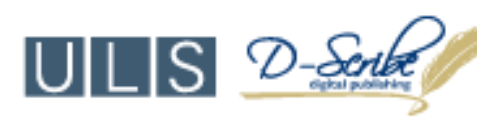

This journal is published by the University Library System, University of Pittsburgh as part of its D-Scribe Digital Publishing Program and is cosponsored by the University of Pittsburgh Press. 